\title{
Neutron Imaging, a Key Scientific Analytical Tool for the Cultural Heritage Project at ANSTO - Investigation of Egyptian Votive Mummies
}

Filomena Salvemini ${ }^{1, a^{*}}$, Constance Lord ${ }^{2, b}$, Candace Richards ${ }^{2, c}$

${ }^{1}$ Australian Nuclear Science and Technology Organization (ANSTO), Lucas Heights, NSW (AU)

${ }^{2}$ Nicholson Museum, University of Sydney, NSW (AU)

afilomena.salvemini@ansto.gov.au, bconstance.lord@sydney.edu.au,

ccandace.richards@sydney.edu.au

Keywords: Neutron Tomography, Non-Invasive Analysis, Cultural Heritage

\begin{abstract}
Neutron imaging has been instrumental in the development of the Cultural Heritage project at ANSTO with many successful applications reported to date. In this study we focus on the investigation of Egyptian votive mummies conducted by combining neutron and X-ray tomography. Two wrapped ibis bundles produced during the Roman Period (30 BC - 364 AD) were studied to inspect their content and ascertain the state of conservation. A new insight in the manufacturing method and composition of the mummified packages was gained in a noninvasive way. Advantages and limitations of the neutron tomographic method were also explored.
\end{abstract}

\section{Introduction}

A strategic scientific research project Cultural Heritage has been initiated at the Australian Nuclear Science and Technology Organization (ANSTO). The project aims to promote the access to the suite of nuclear methods available across the organization, and the use of a noninvasive analytical approach in the field of cultural-heritage, archaeology, and conservation science.

Neutron imaging, in particular, has become a valuable means for research in these fields. The fundamental properties of the neutron - no electric charge, deep penetration power into matter, and interaction with the nucleus of an atom rather than with the diffuse electron cloud -make this sub-atomic particle the ideal probe to non-invasively survey the bulk of a variety of heritage materials, such as metals, pottery, paintings, etc. [1]

In collaboration with Australian museum institutions and universities, and international experts, a series of archaeometric studies involving the neutron imaging beamline DINGO [2] at the Australian Centre for Neutron Scattering (ACNS) has been conducted so far [3] [4] [5]. In this paper, we present a recent tomographic examination of Egyptian votive mummies.

Egyptian mummies have always fascinated the modern world and the ancient Egyptians did not just mummify humans but a vast range of animal species as well [6]. In fact, animal mummies make up the largest category of objects we have from ancient Egypt and yet, until recently, are one of the least researched. In general terms, animal mummies can be divided into four main categories; food or victual mummies, pets, sacred animals and votive (offering) mummies. It is the latter of these that a visitor is most likely to encounter during a visit to an antiquities museum.

Votive mummies are a feature of the first millennium BCE, gaining great popularity in the Late Period and increasing even more so in the Ptolemaic and Roman Periods [7]. In much the same way as conventional offerings for the gods, votive mummies were produced for a range of 
budgets, from simply wrapped figures with no decorative features for the poorer or the more frugal, up to lavishly wrapped mummies complete with cartonnage masks and mummified using an array of expensive embalming products for wealthier members of society or perhaps for a particularly urgent or important request [8].

As a non-invasive scientific method, tomographic investigation of mummies from ancient Egypt has been used since 1896 and provided information on mummification techniques, age and state of health of the individual at the time of death as well as any post-mortem damage to the mummy [9]. Medical Compute Tomography (CT) is commonly employed for these studies, but proved to have limited capabilities in differentiating between skeletal and desiccated soft tissues due to the limitation imposed by inbuilt safety mechanisms concerning radiation dose in human CT.

Neutron tomography, as a complementary method, can expand the investigation capabilities of standard analytical methods. In comparison to X-ray, neutrons feature a different contrast mechanism in the interaction with matter. The neutron attenuation coefficient is high for hydrogen and thus for organic materials. These characteristics make neutron tomography the ideal tool to study soft tissues, embalming substance and bandage of the mummies which mandatory require a non-invasive investigation approach. Moreover, thanks to the high penetration power of probing particles, neutron imaging can provide a unique insight, with high spatial resolution, into the bulk of dense materials, such as most metals and pottery. This enables to investigate the mummified bundle when encased into ceramic containers that is not always achievable with X-ray tomography [10] [11].

\section{Experimental}

\section{Samples}

The investigation was conducted on ibis mummies from the Egyptian antiquities collection of the Nicholson Museum in Sydney, since little scientific data are currently reported on this typology of votive offering.

The samples set consisted of two wrapped ibises and three jars said to contain ibis remains in the museum record. Examination of the content will enable further the scholarly discussion on the purpose of ancient Egyptian fake mummies as well as slightly narrowing the date-range of production as Ptolemy VI Philometer (180 - 168 BC), during an investigation into corrupt practices of the ancient manufacturers of ibis mummies, decreed that, from that time, only one bird per bundle was permitted.

The study is still in progress; here we present preliminary results about the two wrapped ibises (Figure 1-a) based on tomographic analyses, and refer the reader to future publications for a more detailed coverage of the entire research that will include the examination of the jars.

Analytical methods

Neutron tomography and medical CT were combined to characterize the contentment of the two bundles and experimentally explore advantage and limitation of each analytical method.

The neutron tomographic measurements were performed on DINGO. The measurements were conducted in the high-resolution acquisition mode (with the ratio of collimator-detector length $\mathrm{L}$ to inlet collimator diameter D equals to 1000) with a pixel size of $100 \mu \mathrm{m}$ by setting a $200 \times 200$ $\mathrm{mm}^{2}$ field of view with $50 \mathrm{~mm}$ lens coupled with a $100 \mu \mathrm{m}$ thick scintillation screen. Projections were acquired with an equiangular step of $0.1^{\circ}$ over $180^{\circ}$ with an exposure time of 15 seconds each. Since the length of the samples exceed the size of the maximum field of view available on DINGO (sample NM62.584 is $360 \times 180 \times 70 \mathrm{~mm}^{3}$ and sample NM62.585 is 328x130x60 mm ${ }^{3}$ ), 2 consecutive scans with vertical displacement will be acquired for each sample. 
The medical CT analysis with X-rays was conducted at the University of Sydney by setting the $\mathrm{X}$-ray source at $70 \mathrm{kV}$ and acquiring 397 projection equiangularly spaced over $180^{\circ}$ with a pixel size of $\triangleleft 400 \mu \mathrm{m}$.

The data were processed using the Octopus code for tomographic reconstruction [12]. The obtained slices were then recomposed and evaluated using the AVIZO software [13]. Neutron and X-ray data were registered and segmented on the base of the correlation histogram module.

\section{Results and discussion}

The combined application of neutron and X-ray tomographic analyses enable to investigate different aspect of the samples. The content and composition of the mummified packages were clarified; this includes determining the minimum number of individuals wrapped in a single package, and confirmation and identification of any ancient fakes within the set of investigated samples. Identification of species, age, pathologic abnormalities and cause of death can be also inferred on the base of the anatomical features of the animal remains (Figure 1).

Furthermore, more information on the mummification materials and methods can be also obtained as well as evaluation of specimen condition.
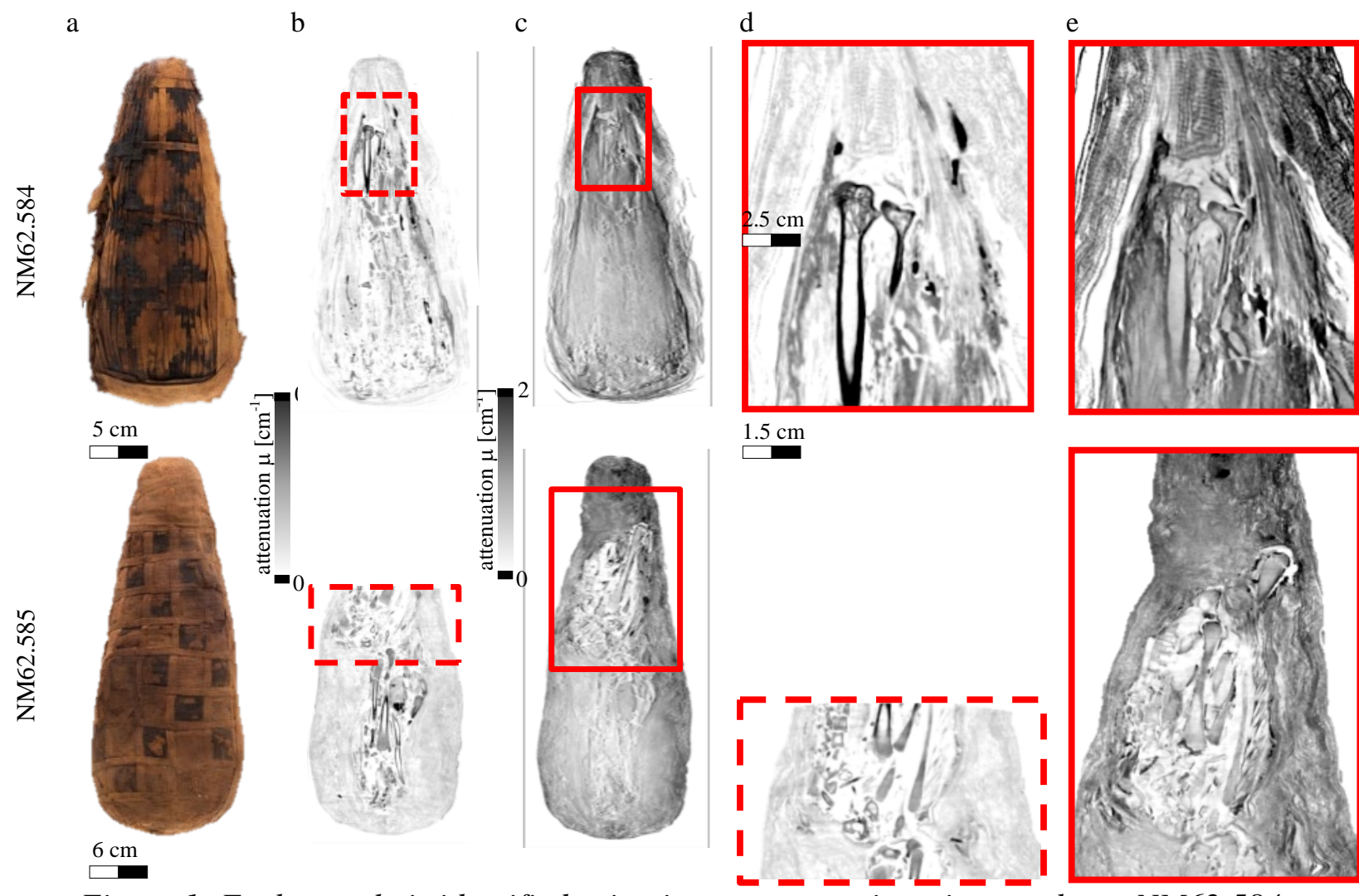

Figure 1: Each sample is identified using its museum registration numbers: NM62.584, NM62.585. a) Photographic images of the wrapped ibises; sections across the b) X-ray and c) neutron tomographic reconstructions and corresponding detailed view of the regions of interested d) and c) are shown. The scale bar at the left of each tomographic section indicates the colour code for the attenuation coefficient. Please, note that the X-ray CT for sample NM62.585 was acquired partially. The provided cross sections highlight the external wrapping enveloping the remains of the ibises, visible in the core area, and the difference in contrast that neutron and $X$-rays can provide for such components. 
The combined tomographic datasets demonstrate the presence of skeletal remains with anatomical features typical of the ibis species in both items. Sample NM62.584 only contains few integral bones in association with several fragmented bones (Figure 2). The wrapping appears quite loose and some linen bandage might have been secured by a pin that was supposedly inserted by previous museum curators in more recent time. The bandage appears to be impregnated with resinous material mostly localised around bones, at the top and the bottom top, and in the outer portions of the wrapping.

a

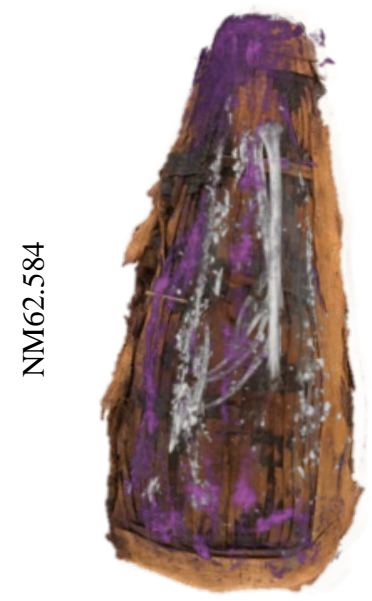

b

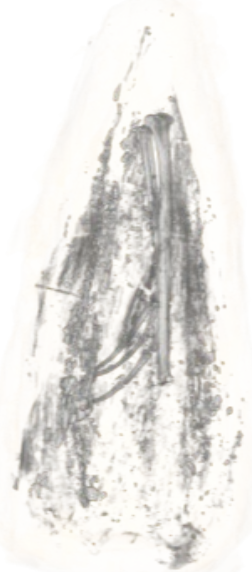

C

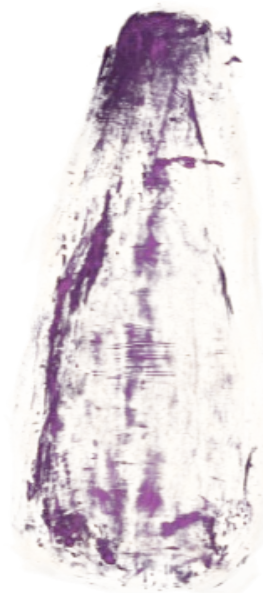

d

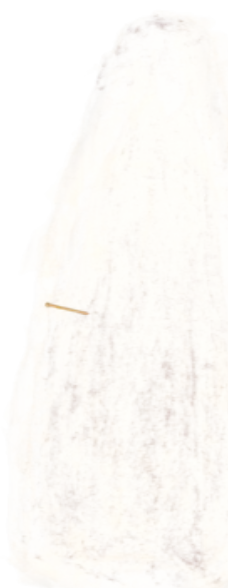

Figure 2: a) The photographic image of the museum item is overlapped to the segmentation based on neutron and X-ray data. The animal remains, distribution of the embalming material in the bandage, and a pin are rendered as separated volume in b), c) and d).

a

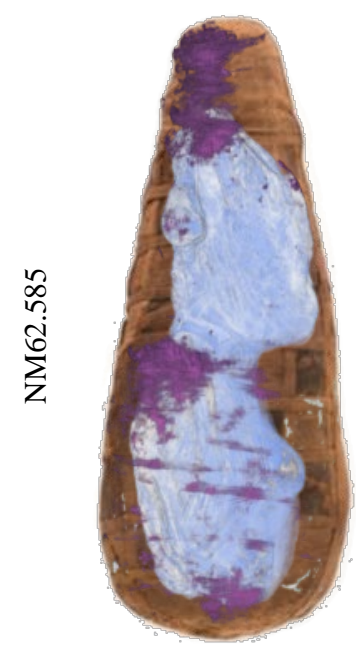

b

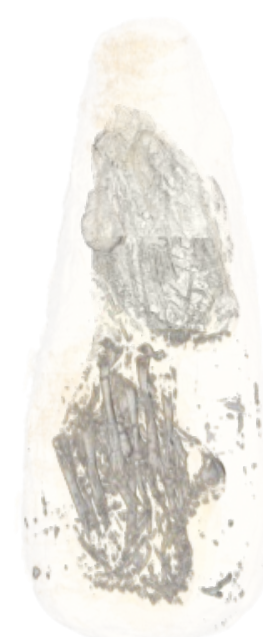

C

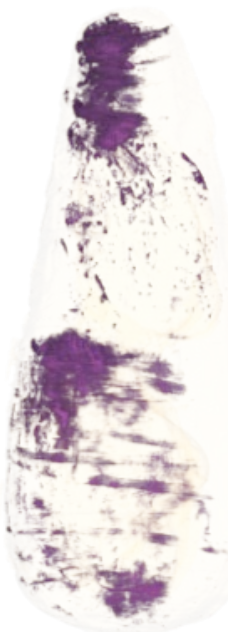

d e

Figure 3: a) The photographic image of the museum item is overlapped to the segmentation based on neutron and X-ray data. The animal remains, distribution of the embalming material in the bandage, feathers, and the stomach content are rendered as separated volume in $b$ ), $c$ ), $d$ ) and $e$ ). 
In the case of sample NM62.585 (Figure 3), the complete skeletons of two individual ibises were identified. Some details such as feathers and the stomach content were also reconstructed. The linen bandage was in better state of conservation and more tightly wrapped. Also in this case, the embalming component was mapped with a distribution similar to sample NM62.584.

The study is still ongoing including consultation with the Australian Museum in Sydney to identify the species and age of ibis.

Some considerations on the analytical method can be also made Figure 1. Neutron tomography demonstrated to be better suitable to detect the presence of feathers, otherwise not visible from the X-ray CT. The resinous balm could be more distinctly mapped due to the high attenuation cross-section of this hydrogen-rich material. Similarly, individual layers of the linen bandage can better be distinguished by neutrons; the tread of the textile and the direction of folding can be discerned to gain a better understanding of the wrapping method. However, limitations of the neutron tomographic method were also evidenced. Especially in the thickest region of the artefact, the neutron beam interacted with very high attenuating materials, such as the balm and several layers of textile; as predicable, in such circumstance, the low counting statistic due to the limited transmission through the sample affected the quality of the tomographic reconstruction. In these portions the tomographic slices are quite nosy and feature of the bulk can be discerned upon treatment of the data - 3D median and anisotropic diffusion filters were applied. X-ray CT has been always the technique of choice to investigate the content of votive offering; its value as analytical tool is hardly arguable as demonstrated by the high contrast offered, especially in the detection of the skeletal remains, and the superior penetration power through the thickest portions of the item. Most of the internal components were visible, despite a lower contrast is observed in the case of balm and textile compared to the neutron tomography. A limitation, intrinsic to the machine adopted for this study rather than the method itself, is the size of the sample that can scan. Figure 1-b shows that only a half of item NM62.585 was investigated since the length of the wrapping exceeded the size of the sample-chamber.

\section{Conclusion}

This study explores the application of a combined approach based on neutron and X-ray tomography to investigate the content of Egyptian votive mummy's part of the collection of the Nicholson Museum in Sydney.

While X-ray is indisputably the analytical method of choice to investigate the contest of such material in a non-invasive way, neutron tomography has demonstrated some advantages. Neutrons offered a better contrast to detect the presence of feathers, to map the distribution of the resinous balm, and to identify individual layers of the linen bandage. On the other hand, the penetration power was quite limited in the thickest portion of the item, thus affecting the image quality.

The investigation provided the museum with valuable information about the content and composition of the mummified packages. The condition of the artefacts was also ascertained; this will greatly assist in the museum's ongoing care and conservation of each of the collection items. The Museum's complete animal mummy collection will be analysed with the same instrumentation to achieve consistency across the collection and allow for comparative analysis between samples where appropriate. Furthermore, it is foretold that the tomographic data will be exploited for the development of 3D visualizations of each specimen for augmentation of museum displays while possible 3D printing of facsimiles will aid further (ongoing) study.

\section{Acknowledgments}

The authors would like to thank the team of Sydney Imaging at the University of Sydney for assistance with the X-ray CT analysis. 


\section{References}

[1] N. Kardjilov and G. Festa, Neutron Methods for Archaeology and Cultural Heritage, Springer, 2017. https://doi.org/10.1007/978-3-319-33163-8

[2] U. Garbe, T. Randall, C. Hughes, G. Davidson, S. Pangelis and S. Kennedy, “A new Neutron Radiography / Tomography / Imaging Station DINGO at OPAL,” in 10 World Conference on Neutron Radiography 5-10 October 2014, 2015.

[3] F. Salvemini, V. Luzin, F. Grazzi, S. Gatenby and M. Kim, "Structural characterization of ancient Japanese swords from MAAS using neutron strain scanning measurements," in Materials Research Forum, 2016.

[4] F. Salvemini, K. Sheedy, S. R. Olsen, M. Avdeev, J. Davis and V. Luzin, "A multitechnique investigation of the incuse coinage of Magna Graecia,” Journal of Archaeological Science: Report, pp. 748-755, 2018. https://doi.org/10.1016/j.jasrep.2018.06.025

[5] F. Salvmeini, V. Luzin, F. Grazzi, S. Olsen, K. Sheedy, S. Gatenby, M.-J. Kim and U. Garbe, "Archaeometric investigations on manufacturing processes in ancient cultures with the neutron imaging station DINGO at ANSTO,” Physics Procedia, vol. 88, pp. 116-122, 2017. https://doi.org/10.1016/j.phpro.2017.06.015

[6] L. Bruno, The Scientific Examination of Animal Mummies in Soulful Creatures, E. Bleiberg, Y. Barbash and L. Bruno, Eds., Brooklyn: GILES, 2013.

[7] S. Ikram, Divine Creatures in Divine Creatures: Animal Mummies in Ancient Egypt, S. Ikram, Ed., Cairo: The American University in Cairo Press, 2005. https://doi.org/10.5743/cairo/9789774248580.001.0001

[8] S. Buckley, K. Clark and R. Evershed, "Complex organic chemical balms of pharaonic animal mummies,” Nature, no. 431, p. 294-9, 2004. https://doi.org/10.1038/nature02849

[9] J. Adams and C. Alsop, Imaging Egyptian Mummies in Egyptian Mummies and Modern Science, R. David, Ed., 21-42, 2008. https://doi.org/10.1017/CBO9780511499654.004

[10] E. Abraham, M. Bessou, L. Szentmiklósi, B. Maryelle and A. Ziéglé, “Terahertz, X-ray and neutron computed tomography of an Eighteenth Dynasty Egyptian sealed pottery," Applied physics. A, no. Materials science processing, 2014. https://doi.org/10.1007/s00339-0148779-3

[11] C. A. Raymond, J. J. Bevitt, Y. Tristant, R. K. Power, A. W. Lanati, C. J. Davey, J. S. Magnussen and S. M. Clark, "Recycled Blessings: an Investigative Case Study of a Rewrapped Egyptian Votive Mummy using Novel and Established 3d Imaging Techniques,” Archaeometry, 2019. https://doi.org/10.1111/arcm.12477

[12] M. Dierick, B. Masschaele and L. Van Hoorebeke, "Octopus, a fast and user-friendly tomographic reconstruction package developed in LabView,” Measurement Science and Technology, vol. 15, no. 7, pp. 1366-1370, 2004. https://doi.org/10.1088/09570233/15/7/020

[13] “FEI,” [Online]. Available: https://www.fei.com/software/amira-avizo/] .

[14] L. Evans L, M. Hartley and C. Lord , Animals in Ancient Egypt: Roles in Life and Death in The Museum of Ancient Cultures Catalogue, Y. Tristant, Ed., Macquarie University Press, in production. 